\title{
Long Memory Modeling: Evidence from Mediterranean Stock Indexes
}

\author{
SAOUSSAN BOUCHAREB, MOHAMMED SALAH CHIADMI, FOUZIA GHAITI \\ Industrial Engineering Department \\ Mohammadia School of Engineering, Mohammed V University \\ Ibn Sina avenue B.P 765, Agdal Rabat 10090 \\ MOROCCO
}

\begin{abstract}
We study in this paper the presence of long memory of four Mediterranean stock markets namely Morocco, Turkey, Spain, and France, over the period 2000-2020. The presence of long memory propriety has tested by using the R/S analysis approach. Results show that the four processes have a long memory. furthermore, ARFIMA-FIGARCH, under different distribution assumptions as Normal, Student-t, and Skewed Student- t, was estimated in order to test the feature of long memory in the return and volatility of the stock markets simultaneously. Results show strong evidence of long memory in both returns and volatility for the Moroccan and French stock markets and only in volatility for The Spanish and Turkish ones. The long memory in returns indicates that their behavior is predictable implying the rejection of the efficient market hypothesis. The long memory in volatility shows that risk is an important parameter of the behavior of the future returns in the four stock markets.
\end{abstract}

Key-Words: - Mediterranean stock indexes, return, volatility, long memory, R/S Analysis, ARFIMAFIGARCH.

Received: March 5, 2021. Revised: September 30, 2021. Accepted: October 18, 2021. Published: November 3, 2021.

\section{Introduction}

Market efficiency has been a subject of much attention in financial literature. With the object of analyzing the presence of long memory, several previous studies were conducted. The first one to demonstrate the existence of long memory in financial markets was Mandelbrot (1971) [1] and he was a key figure in the development of this concept. Later, Greene and Fielitz (1977) [2] study longterm dependence in common stock returns and Granger and Joyeux (1980) [3] have modeled the stochasticity of long memory. The presence of long memory was also confirmed in financial markets by Aydogan and Booth (1988) [4] and later by Cheung and Lai (1995) [5]. There was continuous research indicating the presence of long memory in stock markets done by other authors like Peters (1991, 1994) [6], Alvo and al. (2011) [7] and Lento (2013) [8].

Nevertheless, proof of the fact that long memory might reflect many short memory components has been yield by Lo (1991) [9]. Some researchers show even the non-existence of long memory like Lo (1991) [9], Jacobsen (1995) [10], Berg and Lyhagen (1998) [11], Crato and Ray (2000) [12], Batten and al. (2005) [13] and Serletis and Rosenberg (2007) [14]. Whereas Corazza and Malliaris (2002) [15] and others have reported that it can change over time.
In addition, several works have examined the long memory processes for specific stock markets. First, Koong and al. (1997) [16] showed that long memory does not exist in the four Pacific Basin (Australia, Hong Kong, Singapore, and Japan) stock markets. Whereas Sadique and Silvapulle (2001) [17] prove the existence of long memory in stock market returns for Korea, Malaysia, New Zealand, and Singapore but not for Japan, the USA, and Australia. Kilic (2004) [18] shows, in turn, evidence for ISE 100 index volatility but not for the daily stock returns for Istanbul.

Recently, in 2020, Bala, Anju \& Gupta, Kapil. [19] examine the long memory in stock liquidity and returns in Indian equity market by using data for broad indices from January, 1997 to December, 2019 by applying the hurst exponent (1951) rescaled range analysis. Results show that liquidity series show long memory in Nifty-100, Nifty-200 and Nifty MidCap-50.

In 2021, Lahmiri, Salim \& Bekiros, Stelios. [20] concluded that COVID-19 pandemic significantly influenced long memory in return and volatility of cryptocurrency and international stock markets. Additionally, results show that the model ARFIMAFIGARCH is significantly appropriate to represent returns and volatility of cryptocurrencies and stocks and to disclose differences before and during COVID-19 pandemic periods. 
Actually, various studies have analyzed the long memory characteristics of volatility using data from emerging markets. The general result is that financial returns are martingale with long memory in the conditional volatility process. In spite of the rich literature that investigates the long memory properties of mature stock markets, there is little research that has been provided on the time properties of developing markets. The results of these works indicate evidence of long memory in both stock returns and volatility.

As regards Morocco, even more, rare are the papers that have studied the dynamics of its equity market. For example, Assaf, Ata. (2006) [21] uses the modified rescaled range statistic R/S to test for long memory in the returns and volatility of the MENA region including Morocco. Egypt and Morocco indicate the presence of long memory in the return series, but Jordan and Turkey show negative persistence. For the volatility, the long memory is proved for all series.

Boubaker \& Makram (2012) [22] investigate heavy tails and double long memory for TUNINDEX (Tunisia), MASI (Morocco), and EGX30 (Egypt). The results display the existence of long memory in both returns and volatility. In fact, results reveal that long memory dynamics in the returns and volatility is better modeled by the ARIMA-FIGARCH model. Concerning the Moroccan stock market, the best model for capturing the dual long-memory property in the returns and volatility of MASI is the ARIMA $(1,0.047,2)-F I G A R C H(1,0.257,1)$ model. Thus, the double long-memory model can furnish a better explanation for long-memory dynamics in both returns and volatility.

Assaf (2015) [23], in turn, studies the presence of long memory in returns and volatility of the MENA equity markets, including Morocco. The results indicate evidence of long memory for volatility series, while the returns show weak evidence of long memory. Nevertheless, the returns and volatility measures present less evidence of long memory in the after-crisis period as opposed to the before-crisis period. These findings are explained by the financial and economic conditions that took place in the MENA region after the crisis.

Finally, a recent study by Moulay Driss ELBOUSTY \& Lahsen OUBDI (2020) [24] show also that volatility of Moroccan Stock Market captures the properties of volatility clustering and long memory.

In parallel, our choice of the other three Mediterranean countries (France, Spain, and Turkey) is justified by their strong economic relations with Morocco. France and Spain remain the primary European trade partners, as well as the primary creditors and foreign investors in Morocco. In addition, Turkey and Morocco also enjoy strong economic relations. Following the free trade agreement promulgated in 2006, bilateral trade relations between the two countries over the period 2006-2019 almost tripled to reach US \$ 2.9 billion.

In the case of Turkish stock market, Kasman, Adnan \&Torun, Erdost. (2007) [25] examined the dual long memory property. The results of the ARFIMA-FIGARCH model show strong evidence of long memory in both returns and volatility. Moreover, DiSario, Robert \& Saraoglu, Hakan \& McCarthy, Joseph \& Li, Hsi. (2008) [26] employ wavelets and aggregate series to test for long memory in the absolute value, squared, and log squared daily returns of the Istanbul Index. The three-volatility series are characterized by long memory, indicating that shocks to the stock index volatility decrease slowly and those distant observations are related to each other.

Furthermore, Viviani, Jean-Laurent (2001) [27] analyze the dependence structure of individual stocks returns composing the CAC 40 index using the R/S and modified R/S methods, the Hurst coefficient and the Geweke and Porter-Hudak approach. The results obtained suggest that the hypothesis of a long-term dependence structure cannot be validated.

Mensi, Walid \& Tiwari, Aviral \& Al-Yahyaee, Khamis. (2018) [28] examined the time-varying efficiency of five European GIPSI stock markets (Greece, Ireland, Portugal, Spain, and Italy), compared to global and regional U.S. markets. Results display evidence of long memory in both short and long term for all markets. Additionally, the long memory is more pronounced in the long term than in the short term.

\section{Problem Formulation}

The availability of high-frequency financial data has favored the study of short-term and long-term impacts of a given fluctuation in Financial time series dynamics. These studies made it possible to highlight the concept of long memory often present in economic and financial series.

Thanks to several studies it has been shown that the notion of long memory or long-term dependency exists in the financial market. As a matter of fact, the presence of long memory means that autocorrelations remain significant over a fairly large period of time. On the other hand, this phenomenon contradicts the basics of market efficiency. Lo (1991) [9] thus studied the implications of long 
memory processes in financial theory, and Mignon (1996) [29] studied the impact of this behavior on market efficiency. We recall that the market efficiency hypothesis is associated with the random walk model. The stock market prices follow a random course, and the profitability processes are white noises then: the price observed on the market fluctuates randomly around its fundamental value. Given that the absence of memory is a very restrictive hypothesis empirically, Samuelson suggested in 1965 to replace the random walk model with a martingale model: this model is less restrictive since no condition is then compulsory on the autocorrelations of residues.

Moreover, Fama (1970 and 1991) [30] has shown that short memory does not question the efficiency hypothesis, since the fact that some autocorrelations are significant in the short term cannot be used to speculate. On the other hand, the presence of long memory represents more problems. Poterba and Summers (1989) [31] have studied in detail the phenomenon of return to average prices: after a shock, the price deviates from its fundamental value but always ends up returning to the initial value. This phenomenon implies the possible existence of a difference between the price and the fundamental value. However, if the gap is durable, it can be translated as the presence of long memory.

In fact, Long memory is an important element of financial time series modelling since it is giving interesting insights like the impact of high volatility that might affect market efficiency. Therefore, we can avoid market losses by considering how yesterday's event impacts today's parameters, thanks to the analysis of long memory. This stylized fact can improve returns and volatility forecasting. This implies that we can have better asset valuation and risk management.

The layout of the paper is as follows: A brief literature review is presented in section 2 before describing the methodology used for the analysis in section 3 and then we present the empirical results in the next section. While section 5 contains the concluding comments.

\section{Problem Solution}

\subsection{Methodology}

Diebold and Nason (1990) [32] have shown that the study of financial series reveals a time dependence on risk which often disappears gradually. However, the GARCH type model only models the short-term time dependence which implies an exponential decrease in the effect of shocks over time. The GARCH model is thus a short memory model.

In order to extend the memory of the GARCH model, Engle and Bollerslev (1986) [33] developed an extension of the integrated GARCH model (IGARCH) which represents an explosive memory. This means that the effects of shocks are endlessly persistent. However, since this class of model is not realistic, a third and flexible model was developed by Baillie, Bollerslev and Mikkelsen (1996) [34]. The latter suggested an adjusted version of the two models: The Integrated Fractional GARCH (FIGARCH) Process.

We will first define the concept of long memory mathematically before introducing the FIGARCH model capturing this stochastic property. It is worth remembering that the long memory process is characterized by an autocorrelation function which decreases hyperbolically when the delay increases against short memory processes whose autocorrelation function decreases exponentially.

A stationary process is a long memory process if there is a real number

$$
\begin{gathered}
0<\alpha<\text { and a constant c, c>0 satisfying: } \\
\lim _{k \rightarrow \infty} \frac{\rho_{k}}{c . k^{-\alpha}}=
\end{gathered}
$$

Where is the autocorrelation function and $k$ the delay. Consequently, the autocorrelations of a long memory process verify the following asymptotic relationship:

$$
\rho_{k} \sim c \cdot k^{-\alpha} \text { when } k \rightarrow \text {, The autocorrelations }
$$

decrease in a hyperbolic way.

The presence of long memory in financial series implies the existence of significant long-term autocorrelations. Consequently, the usual assumption of random walk is questioned, also for the white noise property of the profitability series. Long memory notably implies a link between past values and future values of profitability. Past values of returns have lasting consequences on future returns. With that in mind, we can say that past values help shape future returns, which implies the existence of some form of predictability of future returns. This finding is inconsistent with the hypothesis of market efficiency.

\subsubsection{ARFIMA-FIGARCH Model}

The FIGARCH model is presented as follows.

At first glance, we assume that the average is described by the following equation:

$$
y_{t}=\mu_{t}+(1) \text {. }
$$

In order to simplify, we assume that is equal to a constant,$\quad I_{t}$ represents the information 
reviewed until the date t-1 and $\varepsilon_{t} / I_{t-1}$ iid $(0, \quad)$. The conditional residues $\quad \varepsilon_{t} / I_{\mathrm{i}}$ are independent and identically distributed with zero mean and heteroscedastic such as: $\quad E\left(y_{t}\right)=$.

follows a $G A R C H$ process $(p, q)$ if it checks the following three properties:

$$
\begin{aligned}
& \varepsilon_{t}=z_{t} . \\
& E\left(z_{t} / I_{t-1}\right)=, \\
& V\left(z_{t} / I_{t-1}\right)=,
\end{aligned}
$$$$
\text { and checks } \sigma_{t}^{2}=\omega+\alpha(L) \varepsilon_{t}^{2}+\beta(L) \text {. }
$$

where $L$ refers to the delay operator and $\quad \alpha(L)=\sum_{i}^{q} \alpha_{i}$ and $\quad \beta(L)=\sum_{j}^{p} \alpha_{j}$ are two polynomials of $\mathrm{L}$ of respective degrees $\mathrm{q}$ and $\mathrm{p}$. In order to ensure the stability and stationarity of the process, we assume that the roots of the two polynomials $\quad 1-\alpha(L)-\beta$ and $1-\beta$ are outside the unit disc. This condition is satisfied if

$(\alpha+\beta)$ s. The GARCH model (p, q) can be written in the form of an infinite ARCH model, such as:

(2)

$$
\sigma_{t}^{2}=\omega[1-\beta(L)]^{-1}+\alpha(L)[1-\beta(L)]^{-:} .
$$

Given $\quad \sigma_{t}^{2}=\omega[1-\beta(L)]^{-1}+\lambda(L$.

Where

$\lambda(L)=\alpha(L)[1-\beta(L)]^{-1}=\Sigma_{j}^{p} \lambda_{j}$ decreases

exponentially when $\mathrm{j}$ tends towards

The GARCH model (p, q) can be rewritten as an ARMA model $(\mathrm{m}, \mathrm{p})$ such that $\mathrm{m}=\max (\mathrm{p}, \mathrm{q})$

Given $v_{t}=\varepsilon_{t}^{2}-$ the residuals in the conditional variance equation. Using the definition of the model $\operatorname{GARCH}(p, q)$ and by replacing par

$v_{t}+$ we have:

$$
[1-\alpha(L)-\beta(L)] \varepsilon_{t}^{2}=\omega+[1-\beta(L) .
$$

If $[1-\alpha(L)-\beta($ admits a unit root, in this case, our process is not stationary in the sense of GARCH. To overcome these limitations, Engle and Bollerslev (1986) [33] define the integrated IGARCH model. It is written as follows:

$$
(1-L) \phi(L) \varepsilon_{t}^{2}=\omega+[1-\beta(L) \quad \text { where }
$$$$
\phi(L)=\sum_{i=1}^{m-1} \phi_{i} \text {. (4) }
$$

However, this model has an explosive persistence of volatility shocks on the dynamics of the series. Based on the IGARCH model, Baillie, Bollerslev and Mikkelsen (1996) [34l was inspired by the analogy between the ARMA model and the ARFIMA model, to define the FIGARCH model from the GARCH model. The idea is to allow the integration parameter $\mathrm{d}$, which is belonging to $[0,1]$ in the GARCH / IGARCH model, to vary on $[0,1]$. The resulting model is much more flexible: volatility shocks decrease exponentially but are more persistent than the GARCH model and less persistent than the IGARCH model. The FIGARCH model is obtained by replacing the delay operator (1-L) in the last equation with the fractional delay operator $(1-i$. The FIGARCH model $(p ; d ; q)$ is then written as follows: $(1-L)^{d} \phi(L) \varepsilon_{t}^{2}=\omega+[1-\beta(L)$. (5)

where the polynomials $\phi !$ and $1-\beta$ have roots outside the unit circle. The FIGARCH process (p; d; q), just as for $G A R C H(\mathrm{p} ; \mathrm{q})$, admits an $A R C H$ representation. By replacing with its expression and by reorganizing the terms of the above equation, we obtain

$$
\begin{gathered}
{[1-\beta(L)] \sigma_{t}^{2}=\omega+[1-\beta(L)-} \\
\left.(1-L)^{d} \phi(L)\right] \varepsilon_{t}^{2}
\end{gathered}
$$

$$
\begin{aligned}
& \text { or as well } \\
& \quad \sigma_{t}^{2}=\omega[1-\beta(L)]^{-1}+[1-(1- \\
& \left.L)^{d} \phi(L)[1-\beta(L)]^{-1}\right] \varepsilon_{t}^{2}
\end{aligned}
$$

If we note $\lambda$ the polynomial of infinite order such as

$$
\lambda(L)=1-(1-L)^{d} \phi(L)[1-\beta(L) .
$$

FIGARCH model is written then:

$$
\sigma_{t}^{2}=\omega\left[1-\beta(L)^{-1}\right]+\lambda(L \text {. (8) }
$$

Breidt, Crato and De Lima (1998) [35] have adopted another formula for the model. They consider the following GARCH model:

$$
[1-\alpha(L)-\beta(L)]\left(\sigma_{t}^{2}-\sigma^{2}\right)=\alpha(L \text {. (9) }
$$

Where, is the unconditional variance of in the GARCH model. Then they show that the FIGARCH model can be specified as follows:

$$
\phi(L)(1-L)^{d}\left(\sigma_{t}^{2}-\sigma^{2}\right)=\alpha(L \text {. (10) }
$$

Chung (2001) [36] shows that FIGARCH as defined by Baillie, Bollerslev and Mikkelsen (1996) [34] is "inconsistent". He considers $\phi !$ in the equation as:

$$
\phi(L)=1-\sum_{j=1}^{q} \phi_{j} .
$$

Chung analyzes the basic analogy between the ARFIMA model and the FIGARCH model and shows that there are structural differences between the two specifications.

The ARFIMA model was introduced by Granger and Joyeux (1980) [3] and Hosking (1981) [37] to study long memory in the mean equation. A stochastic process follows an ARFIMA process $(\mathrm{a} ; \quad ; \mathrm{m})$ if it checks:

$$
(1-L)^{d_{0}} \psi(L)\left(y_{t}-\mu\right)=\theta\left(L_{*}^{*}\right.
$$

Where is the unconditional mean of , $\psi(L)=1-\sum_{j=1}^{a} \psi_{j}$ and $\quad \theta(L)=1-\sum_{j=1}^{m} \theta_{j}$ are two polynomials of $L$ with respective orders of $a$ and $m$ and is a white noise with a mean 
In order to ensure the stationarity and the invertibility of the process we assume that

varies from -0.5 to 0.5 . This parameter describes the long memory of the process; The fractional difference operator is defined from its development on the basis of Maclaurin series, such as:

$$
\begin{aligned}
& (1-L)^{d_{0}}=1-d_{0} \sum_{j=1}^{\infty} \frac{\Gamma\left(j-d_{0}\right)}{\Gamma(j+1) \Gamma\left(1-d_{0}\right)} L^{j}=1- \\
& \sum_{j=1}^{\infty} \pi_{j}\left(d_{0}\right) L^{j}=1-\delta_{d}(L)
\end{aligned}
$$

Other developments were done for this formula, in order to represent the previous development as an infinite order polynomial of order $L$ such as:

$$
\begin{aligned}
& (1-L)^{d_{0}}= \\
& \sum_{j=0}^{\infty} \frac{\Gamma\left(j-d_{0}\right)}{\Gamma(j+1) \Gamma\left(1-d_{0}\right)} L^{j}=\sum_{j=0}^{\infty} \pi_{j}\left(d_{0}\right) L^{j}
\end{aligned}
$$

$$
\text { Where } \quad \pi_{j}(z)=\frac{\Gamma(j-z)}{\Gamma(j+1) \Gamma(1-z} \text { and is the }
$$
standard gamma function.

The constant of the FIGARCH model is structurally different from in the ARFIMA model. In the latter, the fractional delay operator is applied to the constant. In addition, the long memory structure is different in both models: the memory parameter varies between -0.5 and 0.5 while $d$ belongs to the interval [0.1]

\section{f $\quad 0<d_{0}<1$, ARFIMA model is a stationary long memory model. The autocorrelations are positive, decrease hyperbolically and tend towards 0 when the delay increases. Spectral density is concentrated around low frequencies and tends to infinity when frequencies tend to 0 .}

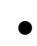

$\mathrm{f} \mathrm{d}_{0}=$, ARFIMA model is reduced to the standard ARMA model.

f $-1 / 2<d_{0}=$, the model is antipersistent, the autocorrelations decrease hyperbolically and tend towards 0 and the spectral density is dominated by the components of the high frequencies.

According to the value of the parameter $d$ in [0.1], the profile and the speed of propagation of the volatility shocks will be determined. If we refer to the analysis of the response functions to derived impulses, we can evaluate the long-term impact of past shocks,$s<t$, on the series according to the limit of the cumulative weights of the impulse response function given by:

\section{$Y(1)=\lim _{k \rightarrow \infty} \sum_{i=0}^{k} Y_{i}=\lim _{k \rightarrow \infty} \lambda_{k}=F(d-$ $1,1,1 ; 1) \phi^{-1}[1-\beta(1)]$}

.(14)

Where $\quad Y_{k}=\frac{\partial E_{t}\left(s_{t+k}^{2}\right)-\partial E_{t}\left(s_{t+\beta}^{a}\right.}{\partial v_{t}}$ is the coefficient of the impulse function, conditional expectation on date $\mathrm{t}$ and $v_{t}=\varepsilon_{t}^{2}-$.

$\bullet$ f $0<d<1$ then $F(d-1,1,1 ; 1)=0$. Hence $Y(1)$ and the volatility shocks decrease hyperbolically unlike the GARCH model where these shocks decrease exponentially;

$\bullet$

f $d=1$ then $F(d-1,1,1 ; 1)=1$. Hence $Y(1)=\phi^{-1}[1-\beta($ and the shocks are infinitely persistent;

\section{$\bullet$}

$\mathrm{f} d>1$ then the conditional variance is explosive and $Y(1) \stackrel{\text { s. }}{\text {. }}$

The memory parameter is applied directly to the square of the error in contrast to the parameter $d$ applied to in FIGARCH. Furthermore, an ARFIMA model $(a ; 0 ; m)$ can be reduced to an ARMA model $(a ; m)$ while a FIGARCH model $(p ; 0$; q) cannot be reduced to a $\operatorname{GARCH}(p ; q)$.

In addition to these structural differences, we can find others technical ones: the parameters of the ARFIMA model are less constrained than those of the FIGARCH model. The latter must satisfy some conditions to ensure the positivity of the conditional variance. While Bollerslev and Mikkelsen (1996) [34] have suggested to add some conditions, while other papers have studied the issue and found other conditions.

There are several methods to study long-term dependence on financial series. Some aim to estimate the exponent of Hurt $\mathrm{H}$ as the $\mathrm{R} / \mathrm{S}$ and modified R/S methods, others like the GPH method (Greweke-Poter-Hudak, 1983) [38] estimate the fractional differentiation parameter $\mathrm{d}$.

\subsubsection{R/S Analysis}

From his study on the Nile, Hurst in 1951 [39], introduced R/S statistics making it possible to detect the presence of long memory. This statistic is defined as the extent $R$ of the partial sums of the deviations of a time series from its mean divided by its standard deviation $S$. 
We consider the time series $X_{t=1_{\text {amm }}}$ with the average . The $\mathrm{R} / \mathrm{S}$ statistic is written then:

$$
\begin{gathered}
R / S=\frac{1}{\left[\frac{1}{T} \Sigma_{J=1}^{T}\left(X_{j}-\overline{\left.X_{t}\right)^{2}}\right]^{\frac{1}{2}}\right.}\left[\operatorname { m a x } _ { 1 \leq k \leq T } \sum _ { j = 1 } ^ { k } \left(X_{j}-\right.\right. \\
\left.\left.\overline{X_{t}}\right)-\min _{1 \leq k \leq T} \sum_{j=1}^{k}\left(X_{j}-\overline{X_{t}}\right)\right]
\end{gathered}
$$

Hurst has shown that R/S statistic is proportional to where $\mathrm{H}$ is called Hurst exponent. We thus obtain an estimate of the latter through the following relation: $\quad H \cong \frac{\log }{\text { lo }}$.

As we previously mentioned, the Hurst exponent allows a classification of series according to their level of dependence. Besides, note that we can also determine a long-term correlation measure linked to the Hurst exponent:

$$
C_{H}=2^{2 H-1} \text {. }
$$

measures the correlation between the average of past observations and the average of future observations in a past and future that can be both described as fairly long. Depending on the value of $H$, we can have a negative, positive or zero correlation.

$\bullet$

f, $\mathrm{H}=1 / 2, C_{H}=$, the process has no long-term dependencies;

-

f $\quad 1 / 2<H<1, C_{H}$; , the process has a long memory. It is worth noting that the closer $\mathrm{H}$ is to 1 , the stronger the dependence is;

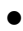

$$
\begin{aligned}
& \text { f } \quad 0<H<\frac{1}{2}, C_{H}{ }^{4}, \text { the process } \\
& \text { represents anti-persistence. }
\end{aligned}
$$

From the $R / S$ analysis, we have an estimate for the persistence of series. However, we do not have a test for the significance of the estimated values. Thus, it is impossible to know if a Hurst exponent estimated to the order of $H=0.51$ for example, is statistically different from 0.5 or not. Therefore, we can conclude that it is difficult to detect a weak long memory.

\subsubsection{Distributions}

It has been shown theoretically and practically that in many cases of normal life and mainly in finance, normality is not always realistic, given the difficulty to understand the dynamism of some economic variables. Consequently, many researchers used different methods, like Ma and Genton (2004) [40] or Bollerslev and Wooldridge (1988) [41] to find other appropriate distributions.

\subsection{Data and empirical Results}

Before estimating the essential Hurst parameter to detect the existence of long memory, we will start with a preliminary analysis of the autocorrelations of the four Mediterranean indexes. The main indexes that constitute the subject of our study are the following:

\section{he MASI index (Moroccan All Shares} Index) is a stock market index that gives the performance of all the shares of the Casablanca Stock Exchange, Morocco. It is the main stock market index of the Casablanca market in addition to the MADEX index (Moroccan Most Active Shares Index).

-

he IBEX 35 is the stock market index for Madrid, Spain. It was created in 1992 and its calculation is based on a weighting by market capitalization comprising the 35 most liquid Spanish stocks.

-

he CAC 40 is a benchmark French stock market index calculated with a weighting of the 40 most important stocks among the 100 largest Parisian market capitalizations.

he BIST 100 index is a stock market index of the Borsa Istanbul stock exchange, the main stock exchange in Turkey. He follows the activities of the Istanbul Stock Exchange, the Istanbul Gold Exchange and the Derivatives Exchange of Turkey.

In this study, we are interested in the daily returns of the four Mediterranean indexes which are computed as the first differences of the natural logarithm multiplied by 100 , of the stock indexes. Our data start from January 3, 2000, and end on June 5, 2020. We have deleted the data of those dates when any series has a missing value. Thereby we have data for the same dates through the stock markets and there are 4385 observations.

We present summary statistics in Table 1 . The return series displays the usual propriety of a small mean and a large standard deviation indicating that it is inconsistent with the normal distribution. Moreover, results show a higher peak and fatter-tail distribution than a normal distribution. This result is confirmed by the Jarque-Bera (JB) test for 
normality. The Ljung-Box test for serial correlation of the 10th order applied to raw and squared returns reject the null hypothesis of no autocorrelation, demonstrating the presence of autoregressive parameters in the return generating processes and heteroscedastic variance for all the markets. In the end, the Augmented Dickey-Fuller (ADF) test supports the hypothesis of stationarity for all return series at the $1 \%$ level.

Table 1. Descriptive statistics of returns.

\begin{tabular}{|l|l|l|l|l|}
\hline & Morocco & Turkey & France & Spain \\
\hline Mean & 0.010137 & 0.020208 & 0.001035 & -0.001150 \\
\hline Std. Dev. & 0.351727 & 0.800350 & 0.640836 & 0.655922 \\
\hline Skewness & 0.831564 & -0.313793 & -0.238838 & -0.313567 \\
\hline Kurtosis & 15.98476 & 8.212622 & 10.30712 & 12.41000 \\
\hline Jarque-Bera & 31303.58 & 5028.370 & 9794.974 & 16239.22 \\
\hline Probability & 0.000000 & 0.000000 & 0.000000 & 0.000000 \\
\hline ADF & $50.85320^{*}$ & $-65.03001^{*}$ & $-67.21441^{*}$ & $-66.09320^{*}$ \\
\hline LB (10) & 317.91 & 1094.4 & 29.724 & 12.012 \\
\hline LB $^{2}(10)$ & 1727.5 & 711.14 & 2004.6 & 1077.6 \\
& & & & \\
\hline
\end{tabular}

* denote significance at the $1 \%$ for all return series.
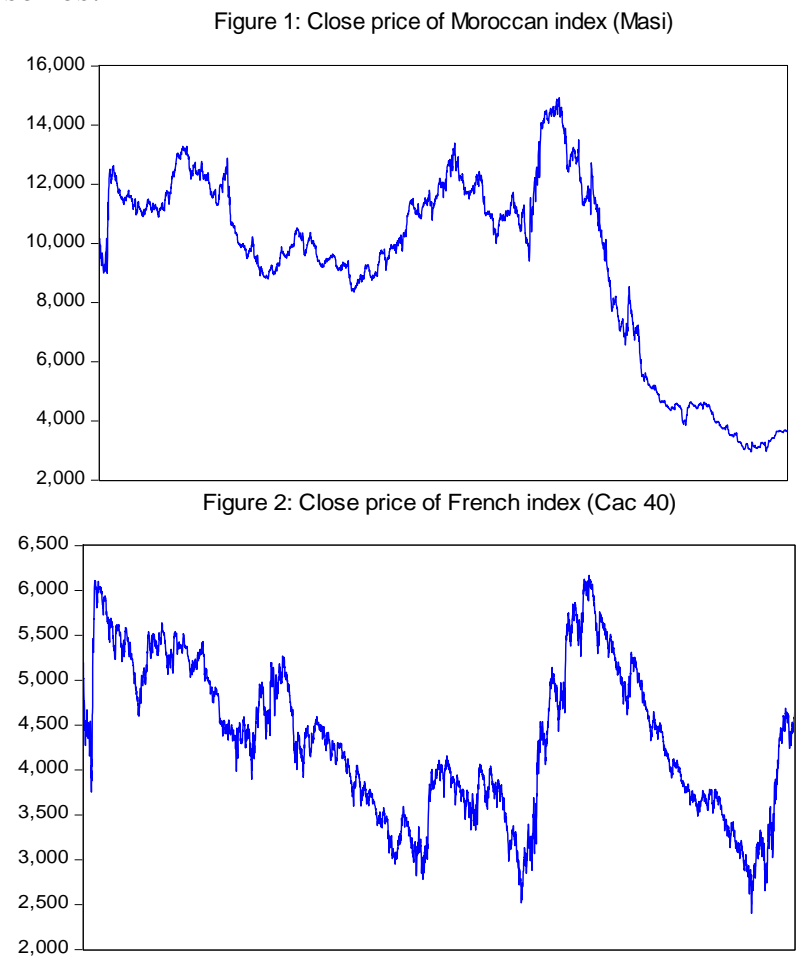

Figure 5: Returns of Moroccan index (Masi)
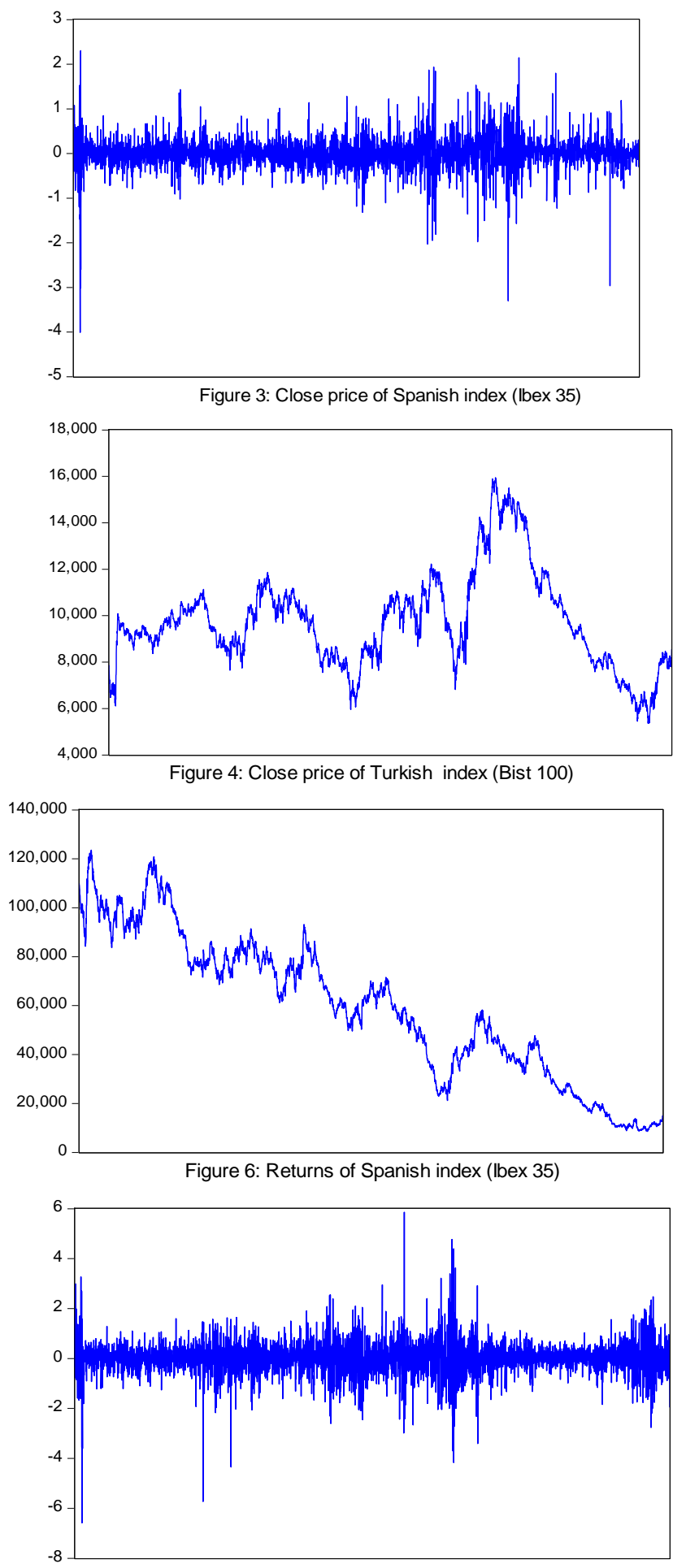


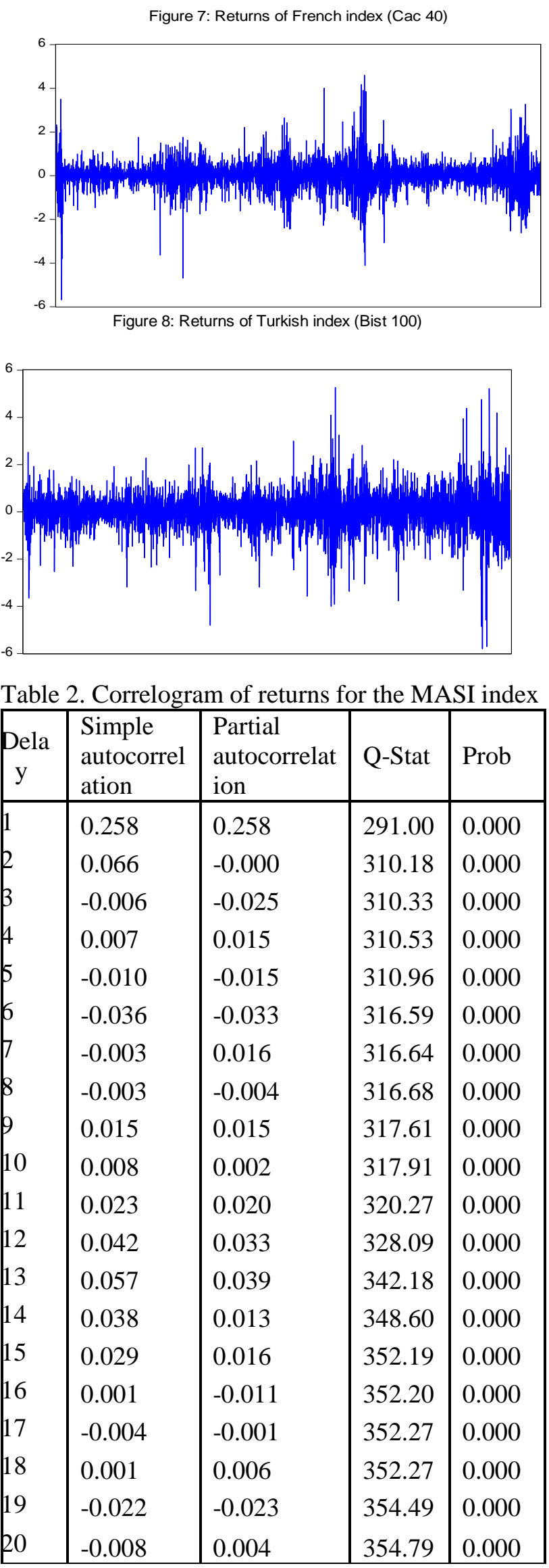

Table 3. Correlogram of the IBEX 35 returns

\begin{tabular}{|lllll|}
\hline $\begin{array}{l}\text { Dela } \\
\mathrm{y}\end{array}$ & $\begin{array}{l}\text { Simple } \\
\text { autocorr } \\
\text { elation }\end{array}$ & $\begin{array}{l}\text { Partial } \\
\text { autocorrel } \\
\text { ation }\end{array}$ & Q-Stat & Prob \\
\hline 1 & -0.486 & -0.486 & 1035.6 & 0.000 \\
2 & -0.017 & -0.331 & 1036.9 & 0.000 \\
3 & -0.008 & -0.264 & 1037.2 & 0.000 \\
4 & 0.026 & -0.185 & 1040.1 & 0.000 \\
5 & -0.024 & -0.172 & 1042.5 & 0.000 \\
6 & -0.005 & -0.168 & 1042.6 & 0.000 \\
7 & 0.031 & -0.113 & 1046.8 & 0.000 \\
8 & -0.019 & -0.106 & 1048.3 & 0.000 \\
9 & 0.001 & -0.095 & 1048.3 & 0.000 \\
10 & -0.005 & -0.095 & 1048.4 & 0.000 \\
11 & -0.002 & -0.102 & 1048.5 & 0.000 \\
12 & 0.001 & -0.102 & 1048.5 & 0.000 \\
13 & 0.023 & -0.061 & 1050.9 & 0.000 \\
14 & -0.023 & -0.070 & 1053.1 & 0.000 \\
15 & 0.014 & -0.048 & 1053.9 & 0.000 \\
16 & 0.005 & -0.021 & 1054.1 & 0.000 \\
17 & -0.026 & -0.046 & 1057.1 & 0.000 \\
18 & 0.008 & -0.049 & 1057.4 & 0.000 \\
19 & 0.028 & -0.003 & 1060.8 & 0.000 \\
20 & -0.032 & -0.026 & 1065.4 & 0.000 \\
\hline
\end{tabular}

Table 4. Correlogram of Bist 100 Returns

\begin{tabular}{|lllll|}
\hline $\begin{array}{l}\text { Del } \\
\text { ay }\end{array}$ & $\begin{array}{l}\text { Simple } \\
\text { autocorrel } \\
\text { ation }\end{array}$ & $\begin{array}{l}\text { Partial } \\
\text { autocorr } \\
\text { elation }\end{array}$ & Q-Stat & Prob \\
\hline 1 & -0.495 & -0.495 & 1076.7 & 0.000 \\
2 & 0.004 & -0.320 & 1076.8 & 0.000 \\
3 & -0.009 & -0.243 & 1077.1 & 0.000 \\
4 & -0.001 & -0.198 & 1077.1 & 0.000 \\
5 & 0.026 & -0.125 & 1080.1 & 0.000 \\
6 & -0.051 & -0.158 & 1091.4 & 0.000 \\
7 & 0.031 & -0.127 & 1095.7 & 0.000 \\
8 & -0.017 & -0.133 & 1097.0 & 0.000 \\
9 & 0.012 & -0.117 & 1097.7 & 0.000 \\
10 & 0.006 & -0.095 & 1097.8 & 0.000 \\
11 & -0.004 & -0.082 & 1097.9 & 0.000 \\
12 & -0.008 & -0.090 & 1098.2 & 0.000 \\
13 & 0.006 & -0.080 & 1098.3 & 0.000 \\
14 & 0.006 & -0.064 & 1098.5 & 0.000
\end{tabular}




\begin{tabular}{|lllll}
15 & -0.005 & -0.057 & 1098.6 & 0.000 \\
16 & 0.002 & -0.046 & 1098.6 & 0.000 \\
17 & 0.005 & -0.027 & 1098.7 & 0.000 \\
18 & -0.010 & -0.029 & 1099.1 & 0.000 \\
19 & -0.004 & -0.037 & 1099.2 & 0.000 \\
20 & 0.009 & -0.025 & 1099.6 & 0.000 \\
\hline
\end{tabular}

Table 5. Correlogram of CAC 40 Returns

\begin{tabular}{|lllll|}
\hline $\begin{array}{l}\text { Del } \\
\text { ay }\end{array}$ & $\begin{array}{l}\text { Simple } \\
\text { autocorr } \\
\text { elation }\end{array}$ & $\begin{array}{l}\text { Partial } \\
\text { autocorrel } \\
\text { ation }\end{array}$ & Q-Stat & Prob \\
\hline 1 & -0.495 & -0.495 & 1075.9 & 0.000 \\
2 & -0.000 & -0.326 & 1075.9 & 0.000 \\
3 & -0.023 & -0.274 & 1078.3 & 0.000 \\
4 & 0.046 & -0.173 & 1087.5 & 0.000 \\
5 & -0.043 & -0.176 & 1095.8 & 0.000 \\
6 & -0.006 & -0.189 & 1095.9 & 0.000 \\
7 & 0.053 & -0.108 & 1108.1 & 0.000 \\
8 & -0.042 & -0.123 & 1115.8 & 0.000 \\
9 & 0.025 & -0.086 & 1118.5 & 0.000 \\
10 & -0.023 & -0.096 & 1120.8 & 0.000 \\
11 & 0.011 & -0.093 & 1121.3 & 0.000 \\
12 & -0.016 & -0.110 & 1122.5 & 0.000 \\
13 & 0.021 & -0.093 & 1124.4 & 0.000 \\
14 & -0.004 & -0.086 & 1124.5 & 0.000 \\
15 & 0.012 & -0.056 & 1125.2 & 0.000 \\
16 & 0.002 & -0.026 & 1125.2 & 0.000 \\
17 & -0.024 & -0.043 & 1127.8 & 0.000 \\
18 & 0.000 & -0.058 & 1127.8 & 0.000 \\
\hline
\end{tabular}


Table 6. Estimation of the double long memory model ARFIMA (1.d.1) -FIGARCH

\begin{tabular}{|c|c|c|c|c|c|c|c|c|c|c|c|c|}
\hline & \multicolumn{3}{|c|}{ Masi } & \multicolumn{3}{|c|}{ Ibex 35} & \multicolumn{3}{|c|}{ BIST 100} & \multicolumn{3}{|c|}{ CAC 40} \\
\hline & Normal & Student & t.skewed & Normal & Student & t.skewed & Normal & Student & t.skewed & Normal & Student & t.skewed \\
\hline$\theta$ & $\begin{array}{l}0.050550 \\
(0.6829)\end{array}$ & $\begin{array}{l}-0.13365 \\
(0.1550)\end{array}$ & $\begin{array}{l}-0.136252 \\
(0.1461)\end{array}$ & $\begin{array}{l}0.133911 \\
(0.7738)\end{array}$ & $\begin{array}{l}0.388533 \\
(0.4744) \\
\end{array}$ & $\begin{array}{l}0.340376 \\
(0.4773)\end{array}$ & $\begin{array}{l}-0.474075 \\
(0.0090)\end{array}$ & $\begin{array}{l}0.745369 \\
(0.0003)\end{array}$ & $\begin{array}{l}0.739515 \\
(0.0004)\end{array}$ & $\begin{array}{l}-0.312779 \\
(0.4107)\end{array}$ & $\begin{array}{l}0.331414 \\
(0.8670)\end{array}$ & $\begin{array}{l}0.159449 \\
(0.8380)\end{array}$ \\
\hline$\omega$ & $\begin{array}{l}0.199110 \\
(0.1980)\end{array}$ & $\begin{array}{l}0.458831 \\
(0.0009) \\
\end{array}$ & $\begin{array}{l}0.454737 \\
(0.0008) \\
\end{array}$ & $\begin{array}{l}0.931295 \\
(0.0219) \\
\end{array}$ & $\begin{array}{r}0.769019 \\
(0.0126) \\
\end{array}$ & $\begin{array}{l}0.811554 \\
(0.0117) \\
\end{array}$ & $\begin{array}{l}0.636818 \\
(0.0002) \\
\end{array}$ & $\begin{array}{l}0.516521 \\
(0.0000) \\
\end{array}$ & $\begin{array}{l}0.511513 \\
(0.0000) \\
\end{array}$ & $\begin{array}{l}0.796874 \\
(0.0287) \\
\end{array}$ & $\begin{array}{l}0.700275 \\
(0.0390) \\
\end{array}$ & $\begin{array}{l}0.723823 \\
(0.0316) \\
\end{array}$ \\
\hline$\alpha$ & $\begin{array}{l}0.150962 \\
(0.8953)\end{array}$ & $\begin{array}{l}-0.14221 \\
(0.6655)\end{array}$ & $\begin{array}{l}-0.152831 \\
(0.6469)\end{array}$ & $\begin{array}{c}0.080517 \\
(0.1503)\end{array}$ & $\begin{array}{l}0.080285 \\
(0.0592)\end{array}$ & $\begin{array}{l}0.074873 \\
(0.0750)\end{array}$ & $\begin{array}{c}0.140991 \\
(0.1587)\end{array}$ & $\begin{array}{l}0.114249 \\
(0.2092)\end{array}$ & $\begin{array}{l}0.114911 \\
(0.2092)\end{array}$ & $\begin{array}{l}0.012900 \\
(0.7751)\end{array}$ & $\begin{array}{l}0.007392 \\
(0.8529)\end{array}$ & $\begin{array}{l}0.002667 \\
(0.9451)\end{array}$ \\
\hline$\beta$ & $\begin{array}{l}0.263878 \\
(0.8432)\end{array}$ & $\begin{array}{l}-0.03687 \\
(0.9177)\end{array}$ & $\begin{array}{l}-0.049952 \\
(0.8902)\end{array}$ & $\begin{array}{l}0.557540 \\
(0.0000)\end{array}$ & $\begin{array}{l}0.570848 \\
(0.0000)\end{array}$ & $\begin{array}{l}0.570072 \\
(0.0000)\end{array}$ & $\begin{array}{c}0.429282 \\
(0.0014)\end{array}$ & $\begin{array}{l}0.375085 \\
(0.0006)\end{array}$ & $\begin{array}{l}0.374571 \\
(0.0006)\end{array}$ & $\begin{array}{l}0.542165 \\
(0.0000)\end{array}$ & $\begin{array}{l}0.557156 \\
(0.0000)\end{array}$ & $\begin{array}{l}0.560168 \\
(0.0000)\end{array}$ \\
\hline$d_{f}$ & & $\begin{array}{l}3.953150 \\
(0.0000)\end{array}$ & $\begin{array}{l}3.946355 \\
(0.0000)\end{array}$ & & $\begin{array}{c}6.110309 \\
(0.0000)\end{array}$ & $\begin{array}{l}6.168599 \\
(0.0000)\end{array}$ & & $\begin{array}{l}7.158359 \\
(0.0000)\end{array}$ & $\begin{array}{l}7.164263 \\
(0.0000)\end{array}$ & & $\begin{array}{l}6.486706 \\
(0.0000)\end{array}$ & $\begin{array}{c}6.646736 \\
(0.0000)\end{array}$ \\
\hline $\mathrm{S}^{*}$ & & & $\begin{array}{l}-0.019458 \\
(0.2767) \\
\end{array}$ & & & $\begin{array}{l}0.046115 \\
(0.0221) \\
\end{array}$ & & & $\begin{array}{l}-0.019639 \\
(0.3472) \\
\end{array}$ & & & $\begin{array}{l}0.072823 \\
(0.0001) \\
\end{array}$ \\
\hline $\mathrm{LL}$ & -798.856 & -501.481 & -500.956 & -3577.653 & -3457.137 & -3454.641 & -4771.546 & -4682.571 & -4682.13 & -3386.817 & -3274.949 & -3268.611 \\
\hline Aic & 0.368091 & 0.232884 & 0.233101 & 1.635791 & 1.581267 & 1.580584 & 2.180450 & 2.140315 & 2.140571 & 1.548730 & 1.498152 & 1.495717 \\
\hline
\end{tabular}


From the results of ARFIMA-FIGARCH model in Table 7, we conclude that the long memory parameter $\boldsymbol{d}_{0}$ in returns is statistically significant for return series of MASI and CAC 40 and not significant for IBEX 35 and BIST 100. The long memory in returns implies that stock prices follow a predictable behavior, which is inconsistent with the efficient market hypothesis.

However, the parameter $\mathrm{d}$ which is the long memory parameter in volatility was found statistically significant for all of distributions and all series. Therefore, a long-term dependence is clearly existent in the variance equation, apart from the type of distribution of residuals. The presence of long memory in volatility indicates that risk is an essential factor of the behavior of daily stock data in the four-stock market.

The finding of long-memory in the volatility of the financial time series suggests the development of new methods of forecasting, portfolio optimization, risk assessing and aggregation.

Given the maximum likelihood estimation function, we can maintain the ARFIMA-FIGARCH model with $\mathrm{t}$ skewed distributions.

\section{Conclusion}

In this study, the presence of a long memory process for four Mediterranean stock market (Morocco, Spain, France, and Turkey) have been examined by estimating the Hurst parameter using the R/S methods and by using ARFIMA-FIGARCH model for the period of 2000-2020.

Firstly, the return series have significant autocorrelations between distant observations which indicate long memory property. Thus, returns are not independent over time and future returns can be predicted by using past prices.

Secondly, the Hurst exponent or Hurst coefficient, the classical parameter characterizing long memory, was estimated. The statistic used is the rescaled range $(\mathrm{R} / \mathrm{S})$ statistic introduced by Hurst (1951) [39]. Results of estimation show clearly that the four financial series have a long-term dependence.

Finally, ARFIMA-FIGARCH model was estimated for different distributions to test long memory property in the return and volatility of the stock markets simultaneously. From results we conclude that the long memory parameter in returns is statistically significant for the Moroccan and the
French stock markets but not significant for the Spanish and Turkish ones.

However, the long memory parameter in volatility was found statistically significant for all distributions and all markets. Therefore, a long-term dependence is clearly existent in the variance equation, apart from the type of distribution of residuals.

Therefore, price movements on the Moroccan and French stock markets are significantly affected by current and historical returns unlike Spanish and Turkish ones. The investment strategies containing equity portfolios must take into consideration all the characterizations of returns in these markets. Our results indicate that the long memory dynamics in volatility is an essential component of the characterization of returns. Indeed, investors must include the dynamics of the financial market in their prediction models.

For the Moroccan market, our results confirm, first, the work of Elbousty, Moulay Driss \&Lahsen, Oubdi [24] showing that volatility of the Moroccan Stock Market captures the properties of volatility clustering and long memory. Second Assaf, Ata. [21] fined also that Morocco shows evidenceof long memory in the return series, while Turkey displays negative persistence. For the volatility series, the long memory is conclusively demonstrated for all MENA markets. In parallel, Natividad Blasco IV \& Rafael Santamaria [4] demonstrate the existence of strong memory processes in the Spanish returns contrary to our results. For the French market, our results confirm also the work of Caporale, Guglielmo Maria\& Gil-Alana, Luis \& Poza, Carlos. [42]

This article confronts two schools of thought in the available literature. The first contains researchers who believe that long memory exists and should be investigated to find the degree of its existence and the second involves those who believe that long memory is an illusion.

To conclude, the theory of efficiency in the financial literature is not always verified. Thus, it is possible to forecast future stock prices and significant gains could be obtained by trading on the four Mediterranean stock markets, contrary to what the efficient markets theory suggests. in this context, the study is an important contribution to applied finance literature in these markets. 


\section{References:}

[1] Mandelbrot, Benoit B. "When Can Price Be Arbitraged Efficiently? A Limit to the Validity of the Random Walk and Martingale Models." The Review of Economics and Statistics 53, no. 3 (1971): 225-36. Accessed January 15, 2021. doi:10.2307/1937966.

[2] Myron T. Greene and Bruce D. Fielitz, (1977), Long-term dependence in common stock returns, Journal of Financial Economics, 4, (3), 339-349.

[3] Granger, C.W.J. et Joyeux, R., 1980, An Introduction to long memory time series models and fractional differencing, Vol 1,15-29.

[4] Aydogan, K. and G.C. booth, 1988, Are there long cycles in common stock returns?, Southern Economic Journal 5:5, 141-149.

[5] Cheung, Y., Lai, S., 1995. A search for long memory in international stock returns. J. lnt. Money Finance 14 (4), 597-615.

[6] Peters, 1991, Chaos and Order in the Capital Markets, John Wiley and Sons, New York (1991)

[6] Peters, 1994, Fractal Market Analysis: Applying Chaos Theory to Investment and Economics, John Wiley and Sons, New York (1994)

[7] Alvo M, Firuzan E, Firuzan AR (2011) Predictability of Dow Jones Index via Chaotic Symbolic Dynamics. World Applied Sciences Journal 12(6):835-839

[8] Lento C (2013) A Synthesis of Technical Analysis and Fractal Geometry - Evidence from the Dow Jones, Industrial Average Components. Journal of Technical Analysis 67:25-45

[9] Lo AW (1991) Long-term memory in stock market prices. Econometrica 59:1279-1313

[10] Jacobsen B (1995) Are Stock Returns Long Term Dependent? Some Empirical Evidence, Journal of International Financial Markets. Institutions and Money 5(2/3):37-52

[11] Berg L, Lyhagen J (1998) Short and Long Run Dependence in Swedish Stock Returns. Appl Financ Econ 8(4):435-443

[12] Crato N, Ray B (2000) Memory in Returns and Volatilities of Commodity Futures' Contracts. J Futur Mark 20(6):525-543

[13] Batten J, Ellis C, Fetherston T (2005) Return Anomalies on the Nikkei: Are They Statistical Illusions? Chaos Solitons Fractals 23(4):11251136

[14] Serletis A, Rosenberg A (2007) The Hurst exponent in energy futures prices. Physica A 380:325-332

[15] Corazza M, Malliaris AG (2002)
Multifractality in Foreign Currency Markets. Multinational Finance Journal 6:387-401

[16] Koong, Albert K. Tsui, W.S. Chan, On tests for long memory in Pacific Basin stock returns, Mathematics and Computers in Simulation, Volume 43, Issues 3-6, 1997, Pages 445-449

[17] Sadique, Shibley \& Silvapulle, Param. (2001). Long-Term Memory in Stock Market Returns: International Evidence. International Journal of Finance \& Economics. 6. 59-67. 10.1002/ijfe.143.

[18] Kiliç, Rehim. (2004). On the long memory properties of emerging capital markets: Evidence from Istanbul stock exchange. Applied Financial Economics. 14. 915-922. 10.1080/0960310042000233638.

[19] Bala, Anju \& Gupta, Kapil. (2020). Examining the long memory in stock returns and liquidity in India. Copernican Journal of Finance \& Accounting. 9 . 25-43. 10.12775/CJFA.2020.010.

[20] Lahmiri, Salim \& Bekiros, Stelios. (2021). The effect of COVID-19 on long memory in returns and volatility of cryptocurrency and stock markets. Chaos, Solitons \& Fractals. 151. 111221. 10.1016/j.chaos.2021.111221.

[21] Assaf. A, Dependene and mean reversion in stock prices: The case of the MENA region, $029^{*}$ Research in International Business and Finance, Volume 20, Issue 3, 2006, Pages 286-304

[22] Adel, Boubaker \& Makram, Beljid. (2013). The empirical relationship between stock returns volatility and trading volume: Evidence on the Tunis stock market. International Journal of Management Science and Engineering Management. $6 . \quad 374-381$. 10.1080/17509653.2011.10671186.

[23] Assaf, Ata, 2015. "Long memory and level shifts in REITs returns and volatility," International Review of Financial Analysis, Elsevier, vol. 42(C), pages 172-182.

[24] Elbousty, Moulay Driss \& Lahsen, Oubdi. (2020). Volatility stylized facts in the Moroccan stock market: Evidence from both aggregate and disaggregate data. 7. 2020.

[25] Kasman, Adnan \& Torun, Erdost. (2007). Long Memory in the Turkish Stock Market Return and Volatility. Central Bank Review. 7. 13-27

[26] Robert DiSario, Hakan Saraoglu, Joseph McCarthy, Hsi Li, Long memory in the volatility of an Hudak emerging equity market: The case of Turkey, Journal of International Financial Markets, Institutions and Money, Volume 18, Issue 4, 2008, Pages 305-312. 
[27] Viviani, Jean-Laurent. Étude de la mémoire longue des actions de l'indice CAC 40. Journal de la société française de statistique, Tome 142 (2001) no. 2, pp. 65-79.

[28] Mensi, Walid \& Tiwari, Aviral \& Al-Yahyaee, Khamis. (2018). An analysis of the weak form efficiency, multifractality and long memory of global, regional and European stock markets. The Quarterly Review of Economics and Finance. 72. 10.1016/j.qref.2018.12.001.

[29] Mignon (1996) Les implications de la mémoire longue et de la non-linéarité sur l'efficience du marché des changes, Journal de la société statistique de Paris, tome 137, no 1 (1996), p. 51-72

[30] Eugene Fama, (1970), Efficient Capital Markets: A Review of Theory and Empirical Work, Journal of Finance, 25, (2), 383-417

[30] Eugene Fama, (1991), Efficient Capital Markets: II, Journal of Finance, 46, (5), 1575617

[31] Poterba, James \& Summers, Lawrence. (1989). Mean Reversion in Stock Prices: Evidence and Implications. Journal of Financial Economics. 22. 27-59. 10.1016/0304-405X(88)90021-9.

[32] Diebold, Francis and Nason, James, (1990), Nonparametric exchange rate prediction, Journal of International Economics, 28, issue 34, p. 315-332.

[33] Engle, R.F. and Bollerslev, T. (1986) Modelling the Persistence of Conditional Variance. Econometric Reviews, 5, 1-50.

[34] Richard T. Baillie, Tim Bollerslev, Hans Ole Mikkelsen, Fractionally integrated generalized autoregressive conditional heteroskedasticity, Journal of Econometrics, Volume 74, Issue 1, 1996, Pages 3-30.

[35] Breidt, F. Jay, Crato, Nuno and de Lima, Pedro, (1998), The detection and estimation of long memory in stochastic volatility, Journal of Econometrics, 83, issue 1-2, p. 325-348.

[36] Chung, Ching-Fan. (2001). Calculating and Analyzing Impulse Responses for the Vector ARFIMA Model. Economics Letters. 71. 17-25. 10.1016/S0165-1765(00)00399-2.

[37] J.R.M. Hosking, Fractional differencing. Biometrika., 68 (1981), pages 165-176.

[38] Geweke, John \& Porter-, Susan. (2008). The Estimation and Application of Long Memory Time Series Model. Journal of Time Series Analysis. 4. 221 - 238. 10.1111/j.14679892.1983.tb00371.x.

[39] Hurst, H.E. (1951) The Long-Term Storage Capacity of Reservoir. Transactions of the American Society of Civil Engineers 116, Paper
2447, Published in 1950 as ProceedingsSeparate No. 11.

[40] Ma, Yanyuan \& Genton, Marc. (2004). Flexible Class of Skew-Symmetric Distributions. Scandinavian Journal of Statistics. 31. 459-468. 10.1111/j.14679469.2004.03_007.x.

[41] Bollerslev and Wooldridge, (1988), QuasiMaximum Likelihood Estimation of Dynamic Models with Time-Varying Covariances, No 505, Working papers, Massachusetts Institute of Technology (MIT), Department of Economics

[42] Caporale, Guglielmo Maria \& Gil-Alana, Luis \& Poza, Carlos. (2019). High and low prices and the range in the European stock markets: A long-memory approach. Research in International Business and Finance. 52. 101126. 10.1016/j.ribaf.2019.101126.

\section{Creative Commons Attribution License 4.0 (Attribution 4.0 International, CC BY 4.0)}

This article is published under the terms of the Creative Commons Attribution License 4.0 https://creativecommons.org/licenses/by/4.0/deed.en US 